\title{
Casa e trabalho: tensões e arranjos no cotidiano de trabalhadoras domésticas
}

\section{Home and work: tensions and arrangements in everyday life of domestic workers}

\author{
Marta Maria Valeriano \\ mmvaleriano2015@gmail.com \\ Universidade Federal de Goiás, Brasil \\ (iD) Tania Ludmila Dias Tosta \\ tania_tosta@ufg.br \\ Universidade Federal de Goiás, Brasil \\ (iD Jordão Horta Nunes \\ jordao_fcs@ufg.br \\ Universidade Federal de Goiás, Brasil
}

Recepção: 31 Julho 2020

Aprovação: 13 Novembro 2020

Publicación: 01 Marzo 2021

Citasugerida: Valeriano, M. M., Tosta, T. L. D. y Nunes, J. H. (2021). Casa e trabalho: tensões e arranjos no cotidiano de trabalhadoras domésticas. Descentrada, 5(1), e133. https://doi.org/10.24215/25457284e133
Resumo: Este artigo discute a relação trabalho e família vivenciada por trabalhadoras domésticas no Brasil a partir de análise de bases de dados governamentais e entrevistas semiestruturadas com trabalhadoras domésticas. A pesquisa indica que as trabalhadoras acumulam trabalho doméstico remunerado e não remunerado ou recorrem a outros arranjos que não alteram a dinâmica de relações de subordinação e as normas de gênero na articulação entre trabalho e família. A ampliação e efetivação da legislação trabalhista para a categoria requer políticas que visem a socialização e a desgenerificação dos custos do cuidado.

Palavras-chave: Trabalho doméstico, Gênero, Famílias, Arranjos domésticos, Brasil.

Abstract: This article discusses the work-family relationship as experienced by women in domestic services in Brazil based on an analysis of governmental databases as well as semistructured interviews with domestic workers. The research indicates that female domestic workers accumulate paid and unpaid housework or resort to other arrangements that do not alter the subordination dynamics or the gender norms in the articulation between work and family. Our results suggest that the expansion and enforcement of labor legislation for the occupational category requires policies aimed at socializing and degenderizing the costs of care.

Keywords: Domestic labor, Gender, Families, Household arrangements, Brazil.

Resumen: Este artículo discute la relación entre trabajo y familia experimentada por trabajadoras domésticas en Brasil a partir del análisis de bases de datos gubernamentales y entrevistas semiestructuradas con trabajadoras domésticas. La investigación demuestra que las trabajadoras concentran trabajo doméstico remunerado y no remunerado o acuden a otros arreglos que no alteran la dinámica de subordinación ni las normas de género en la articulación entre trabajo y familia. Una ampliación y efectivización de la legislación laboral para esta categoría requiere políticas que apunten hacia la socialización y la desgenerización de los costos del cuidado.

Palabras clave: Trabajo doméstico, Género, Familias, Conciliación doméstica, Brasil. 


\section{INTRODUCCIÓN}

A produção sociológica sobre o trabalho em serviços domésticos no Brasil e na América Latina enfatiza sobretudo relações de informalidade, precariedade, subalternidade e ambiguidade na identidade ocupacional/profissional (Bruschini, 2006; Brites, 2013; Gorbán \&Tizziani, 2014; Pérez, Cutuli \& Garazi, 2018). Recentemente manifesta-se um interesse por novos temas, sobre a contratação de imigrantes, relações de trabalho no mundo globalizado e a questão do trabalho afetivo ou emocional (Gutiérrez-Rodríguez, 2014). Pretende-se aqui privilegiar uma questão não menos importante, a construção de arranjos domésticos e de formas identitárias em domicílios de trabalhadoras domésticas, ressaltando o fato de que apenas 6,85\% das pessoas que desempenharam trabalhos domésticos de janeiro a março de 2020 no Brasil eram homens, de acordo com dados da Pesquisa Nacional por Amostra de Domicílios (PNAD Contínua) ${ }^{1}$ realizada pelo Instituto Brasileiro de Geografia e Estatistica - IBGE. Deslocamos a tradicional ênfase na relação entre empregadas e patroas ${ }^{2}$ em que o papel em geral subalterno e invisível das primeiras é inquestionável, para outro foco, o das famílias de trabalhadoras domésticas, em bairros periféricos ou em outras cidades e estados.

A situação das trabalhadoras domésticas no Brasil é bastante preocupante. Da estimativa de 4.197.532 mulheres ocupadas como domésticas no início de 2020, 52\%, ou quase 2 milhões e 200 mil trabalhadoras, foram consideradas pessoas de referência em seus domicílios e o rendimento mensal médio dessas mulheres, “chefes" em seus domicílios, responsáveis pela maior parte do orçamento familiar, era de 954 reais, ${ }^{3}$ inferior ao salário mínimo na época (1045 reais). Nesses domicílios em que trabalhadoras domésticas são pessoas de referência a estimativa do tipo predominante de família em 2015 era o de casal com todos os filhos maiores de 14 anos (19,68\%), seguido por mães não casadas com filhos maiores de 14 anos (16,81\%). Três quartos dessas trabalhadoras como pessoas de referência têm mais de 38 anos de idade. Outro lado dessa distribuição de arranjos familiares de trabalhadoras domésticas está na manutenção, ainda que residual, do grupo daquelas que residem nos domicílios de seus patrões, estimado em 70.751 pessoas no Brasil em 2015, segundo a PNAD. ${ }^{4}$ Embora a ocupação nesse grupo manifeste uma tendência de decréscimo (estimado em 33.450 mulheres no primeiro trimestre de 2020), essa situação, em que a ambiguidade da identidade ocupacional é mais evidente, está relacionada a arranjos familiares específicos, na casa do/as patrões/as e também nos domicílios das famílias de origem das trabalhadoras, ainda pouquíssimo analisada na literatura sobre serviços domésticos.

Os diversos estudos voltados à problemática da conciliação e arranjos domésticos têm dado pouca atenção à trabalhadora doméstica, minimizando o fato de que as próprias trabalhadoras também articulam trabalho e afazeres domésticos/familiares, nesse caso, trabalho doméstico remunerado e não remunerado. $\mathrm{O}$ enorme contingente de mulheres realizando o trabalho doméstico possibilitou a articulação do trabalho produtivo e reprodutivo para as mulheres das classes privilegiadas, ao mesmo tempo em que camuflou as tensões originárias da rígida divisão sexual do trabalho no seio dessas famílias. A divisão do trabalho sustentada pelas relações de gênero separa e hierarquiza as diferentes atividades de trabalho com base numa suposta diferença natural entre os gêneros. Às mulheres são atribuídas as atividades reprodutivas realizadas no âmbito doméstico/familiar, para benefício do grupo social de homens que se veem em condições de se dedicarem ao trabalho produtivo, realizado na esfera pública (Kergoat, 2009). Desse modo, a externalização do trabalho doméstico libera as mulheres das classes médias e altas para a realização do trabalho produtivo, mas condiciona mulheres em condições subalternas ao trabalho precário e à dupla e até tripla jornada de trabalho. 
Por outra via analítica, o trabalho doméstico remunerado pode ser entendido como uma ocupação que propiciou, ainda que em condições precárias, renda e autonomia para as mulheres das camadas mais pobres da sociedade, em geral migrantes e com pouca escolaridade. Com dificuldades de inserção em outras ocupações, esse enorme contingente de mulheres que, em muitos casos, são responsáveis economicamente pelas famílias, encontra no trabalho doméstico remunerado a porta de entrada para o mercado de trabalho, constituindose muitas vezes uma ocupação para a vida toda (Melo, 1998; Valeriano, 2017).

A relação trabalho e família vivenciada por trabalhadoras domésticas apresenta algumas especificidades: 1) as atividades exercidas no trabalho não diferem das atividades realizadas em seus lares, para suas famílias, ou seja, a conciliação se dá entre trabalho reprodutivo remunerado e não remunerado (Ávila, 2009); 2) o elemento central desses trabalhos, a saber: o âmbito doméstico/privado, no qual as atividades são realizadas, se configura também como o seu principal elemento de desvalorização social (Gorbán y Tizziani, 2019); 3) a conciliação se efetiva(va) sob um tempo indeterminado de trabalho remunerado, pois só recentemente a categoria conquistou a regulamentação da jornada de trabalho; 4) no caso das trabalhadoras domésticas que residem no local de trabalho, a migração e a formação de arranjos que lhes possibilitam residir no local de trabalho aliam-se a essas características mencionadas. Ademais, o trabalho aliado à moradia incide significativamente sobre o tempo em que as domésticas residentes dedicam à família.

Com base nesses pressupostos, este artigo visa analisar a relação trabalho e família vivenciada por mulheres em serviços domésticos no Brasil. A ênfase incide sobre arranjos domésticos no domicílio de origem das trabalhadoras, pensando principalmente no caso de domésticas que migraram de cidades do interior ou de outros estados. A metodologia recorreu a técnicas quantitativas e qualitativas, entre elas: levantamento e análise da literatura, seleção e análise em bases de dados governamentais (PNAD e PNAD Contínua) e entrevistas semiestruturadas com 13 trabalhadoras domésticas. O emprego de dados quantitativos e qualitativos visa compreender os aspectos objetivos e subjetivos que permeiam a relação trabalho e família vivenciada por trabalhadoras domésticas. A triangulação de diferentes técnicas possibilitou também a análise do contexto específico (Goiânia) em relação ao mercado de trabalho nacional, no setor considerado.

Goiânia, capital do estado de Goiás, na região Centro-Oeste do Brasil, tem população estimada de 1.516.113 pessoas, segundo o Instituto Brasileiro de Geografia e Estatística (IBGE). A cidade possui um intenso fluxo migratório, acolhendo, principalmente, migrantes do nordeste brasileiro e das cidades do interior de Goiás. O relatório ONU-Habitat (2010) classificou Goiânia como a cidade mais desigual da América Latina. Segundo o IBGE, em 2018, 27\% da população da cidade estava em domicílios com rendimentos mensais de até meio salário mínimo por pessoa. Além das características sociodemográficas apontadas que fazem de Goiânia um caso relevante para a análise proposta, a escolha da cidade se justifica por estar fora do eixo central privilegiado pelas pesquisas sobre a temática no Brasil, constituindo-se num cenário ainda pouco estudado.

Para a investigação qualitativa foram entrevistadas 7 trabalhadoras domésticas residentes (que residem no local de trabalho) e 6 diaristas, na cidade de Goiânia, entre os anos de 2015 e 2017. Para proteção da identidade das entrevistadas, usaremos nomes fictícios ao citar suas falas, conforme exigência da Comissão Nacional de Ética em Pesquisa do Brasil. Partiu-se de um roteiro pré-estabelecido em que se buscou abordar questões referentes à trajetória pessoal e profissional, organização doméstica e familiar, condições de trabalho e identidade ocupacional. A amostragem foi em bola de neve, técnica que segundo Juliana Vinuto (2014), se faz útil nos casos em que há dificuldade de acesso à população a ser estudada ou que não há precisão sobre sua quantidade.

Os estudos sobre o trabalho doméstico remunerado alimentam uma produção acadêmica considerável, abarcando uma variedade de subtemas e questões (Brites, 2007; Bernardino-Costa, 2015; Vieira \& Almeida, 2019; Vazquez Lorda \& Pérez, 2019; Acciari \& Pinto, 2020). Ao que tudo indica, finalmente reconheceu- 
se a relevância da temática para a compreensão das sociedades e de suas nuanças. Entretanto, algumas questões permanecem ainda pouco exploradas, é o caso dos arranjos domésticos nas famílias das trabalhadoras domésticas, a que esse estudo se dedica.

\section{O TRABALHO DOMÉSTICO REMUNERADO: NOVAS DINÂMICAS, INSISTENTES PERMANÊNCIAS}

O trabalho doméstico remunerado é fruto do entrecruzamento das desigualdades de gênero, raça, classe e origem geográfica (Brites, 2013). É também, segundo Gorbán e Tizziani (2019, p.12) “un lugar crítico para reflexionar en torno de la manera en que se construyen y se reproducen, en la práctica cotidiana, mecanismos de diferenciación y de jerarquización social, basados en el género, la clase, la etnicidad y la racialidad". Essas afirmações são comprovadas ao considerarmos o perfil das trabalhadoras domésticas na América Latina e Caribe, onde, segundo dados da Comissão Econmica para América Latina e o Caribe (ONU Mulheres, OIT, CEPAL, 2020), entre 11 e 18 milhões de pessoas se dedicam ao trabalho doméstico, destas $93 \%$ são mulheres, $77,5 \%$ estão na informalidade, $17 \%$ são migrantes e $63 \%$ negras. Esta distribuição ainda é corroborada na análise dos perfis das trabalhadoras domésticas retratadas neste estudo, tanto em nível nacional, como na cidade de Goiânia.

Observou-se que o perfil das trabalhadoras entrevistadas se distingue conforme o vínculo na ocupação. No que tange à idade, as residentes se concentram na faixa etária que vai de 19 aos 30 anos e as diaristas de 39 aos 62 anos. As residentes apresentam melhor grau de escolarização, todas possuem ao menos o Ensino Médio; entre as diaristas duas concluíram apenas o Ensino Fundamental e quatro têm Ensino Médio (concluídos recentemente através da modalidade Educação de Jovens e Adultos - EJA). Todas as entrevistadas migraram para Goiânia em busca de melhores condições de vida. Oito das treze entrevistadas se autodeclararam pretas e pardas.

Os dados da PNAD Contínua referentes ao $1^{\circ}$ trimestre de 2020 estimam em Goiânia aproximadamente 22.119 mulheres no trabalho doméstico remunerado, sendo $70 \%$ negras (pretas e pardas). Diferentemente do perfil etário das residentes, em média mais jovens, a média de idade das trabalhadoras domésticas (em todos os vínculos e modalidades) é de 49 anos, acima da média nacional, e $51 \%$ são responsáveis pelos domicílios (contribuem com todo ou a maior parte do orçamento doméstico). A faixa modal de escolaridade é o ensino fundamental incompleto e $29 \%$ completaram o ensino médio completo.

No delinear da história sobre o trabalho doméstico no Brasil observa-se que este, com raízes no sistema escravista (Mattoso, 1982; Graham, 1992; Ávila, 2009), manteve e atualizou as bases sob as quais as desigualdades foram e são (re)construídas e sustentadas, respondendo às novas dinâmicas e demandas sociais ao mesmo tempo em que as produzem. Ainda é lugar comum a constatação de que o trabalho doméstico remunerado no Brasil permanece como uma ocupação exercida majoritariamente por mulheres negras, de classes menos favorecidas e com pouca escolaridade. Permanece também, mesmo após o alargamento dos direitos trabalhistas da categoria, como uma das ocupações mais precárias no país, sobretudo pelo elevado índice de informalidade e baixos rendimentos auferidos.

Ligada aos arranjos e desarranjos familiares, a inserção dessas mulheres na ocupação acontece, seja na infância ou na vida adulta, como resultante da necessidade de a mulher contribuir com o orçamento familiar ou de assumir economicamente a família, ou ainda, como uma alternativa para a não dependência familiar (no caso das domésticas jovens, solteiras e sem filhos). Entretanto, ambos os casos têm como pano de fundo a pobreza, os subempregos familiares, o abandono escolar, a divisão sexual do trabalho, desigualdades de gênero e raça, fazendo com que a ocupação lhes seja uma das poucas alternativas.

Até a metade do século XX a maioria das/os trabalhadoras/es domésticas/os era composta de mulheres jovens, migrantes do campo e com baixos níveis de instrução. Moravam na residência em que trabalhavam, sendo denominadas domésticas residentes e popularmente: "criadas", ou em alguns países da América Latina 
“cama adentro" (Borgeaud-Garciandía, 2017). Atualmente esse contingente de trabalhadoras domésticas tende a se tornar cada vez menor, como se mostrará na Tabela 1.

Conforme já observado, há especificidades no perfil das trabalhadoras domésticas residentes no local de trabalho que favorecem a sua permanência na casa dos patrões. Trata-se, nesses casos, de mulheres jovens, migrantes, solteiras e sem filhos. Sem vínculos familiares nas cidades em que residem e trabalham, a moradia na casa dos patrões é vista como uma vantagem pelo fato de não precisarem pagar aluguel e arcar com as despesas de alimentação. No entanto, para a maioria delas a condição de moradora é considerada um arranjo provisório até atingirem uma estabilidade econômica ou formarem suas famílias. Esse tipo de arranjo torna-se desfavorável quando a trabalhadora residente se torna mais escolarizada, casa-se ou tem filhos. Assim, embora trabalhadoras mais velhas tenham experienciado morar no local de trabalho no início de suas trajetórias, é cada vez menor o número das que permanecem nessa condição. Uma evidência disso está na distribuição etária de residentes, vista longitudinalmente. A Figura 1 ilustra o progressivo "envelhecimento" da categoria de residentes. Em 2003 mais de 75\% de trabalhadoras domésticas que residiam no domicílio de empregadores/as tinha menos de 40 anos e no primeiro trimestre de 2020 cerca de $50 \%$ da distribuição têm idade inferior a 40 anos.

FIGURA 1

Idade de trabalhadoras domésticas residentes - Brasil - 2003 e 2020-1

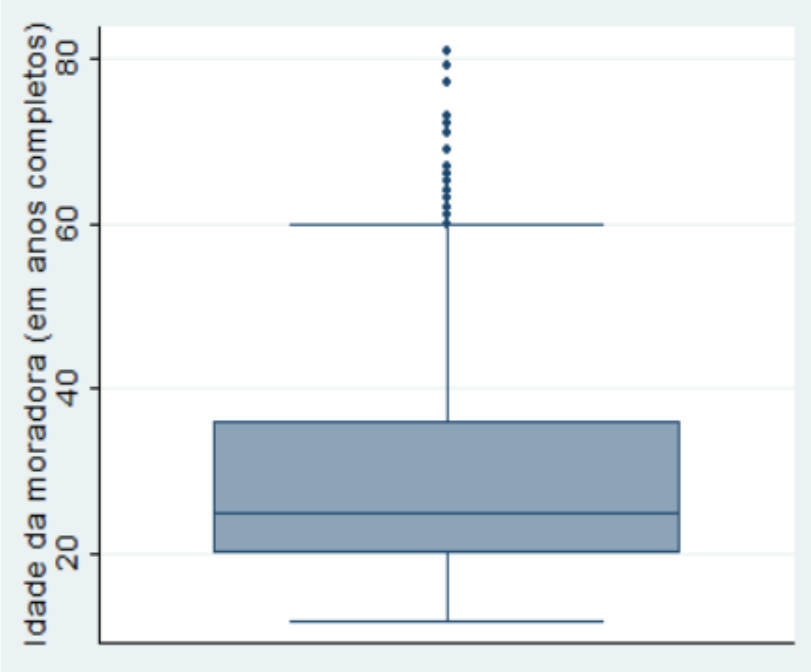

2003

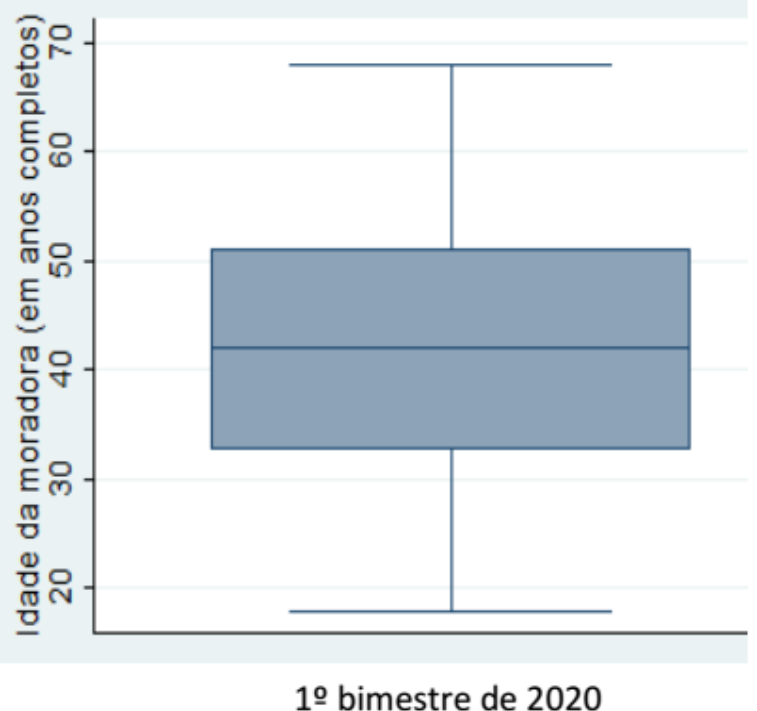

1 을 bimestre de 2020

IBGE, microdados da PNAD e da PNADC, elaboração própria

Amparadas agora pela legislação, essas trabalhadoras são aquelas que vivenciam de forma mais intensa a proximidade e afetividade construídas nas relações de trabalho. E, por esse motivo, as formas contratuais são contornadas por trocas de favores, pela negociação do tempo livre e da remuneração, entre outros elementos que fazem parte do que Jurema Brites (2007) denominou de ambiguidades afetivas. As domésticas mensalistas não residentes também experimentam essas formas ambíguas nas relações de trabalho, embora de forma menos intensa do que as residentes, pois, cotidianamente, vivenciam a separação temporal e espacial entre trabalho e não-trabalho. Segundo Hildete Melo:

A situação dos trabalhadores externos/diaristas na categoria representa uma forma mais clara de relações de trabalho assalariado (com ou sem carteira). Permite demarcar as relações de classe, enquanto os trabalhadores domésticos residentes têm essa relação dissimulada: o alojamento e a comida são vistos como uma regalia dos patrões. Ademais, para as externas/diaristas é possível separar mais facilmente a jornada de trabalho e definir melhor a relação patroa/empregada (1998, p.12). 
Atualmente, embora o maior número de trabalhadoras domésticas se enquadre na categoria mensalista não-residente, o número de diaristas é expressivo e crescente. Estas não foram amparadas pela lei que alargou os direitos das trabalhadoras domésticas e estão na ponta mais precária da ocupação. A maioria dessas trabalhadoras não tem registro na carteira, não goza de direitos que as outras trabalhadoras possuem, geralmente trabalha em mais de um domicílio ou exerce outras atividades remuneradas para complementação da renda, vivenciando muitas vezes triplas jornadas de trabalho. Essas jornadas, por sua vez, são caracterizadas como intensas, incertas e flexíveis, fazendo com que todas as atividades de não-trabalho fiquem à mercê do tempo de trabalho (Bento, 2016; Monticelli, 2013; Ávila, 2009).

As atividades de trabalho realizadas pelas mensalistas são melhor distribuídas ao longo do dia e da semana, permitindo decidir o dia em que irão realizar determinada tarefa. Já a diarista tem o seu tempo de trabalho intensificado, pois precisa "dar conta" de todo o trabalho a ser realizado, em um só dia, e em um determinado tempo. A quantidade de casas que a diarista atende determinará também o grau de intensificação do tempo de trabalho, entendida não apenas como dispêndio da capacidade física, mas também das capacidades psíquica, emocional, cultural e relacional (Dal Rosso, 2008; Cardoso, 2013). Considerando, portanto, conforme Ana Cláudia Cardoso (2013, p.368) que a análise da intensidade do tempo de trabalho deve partir da "vivência do sujeito em relação à carga de trabalho/nível de esforço, por um determinado período, num contexto organizado localmente e socialmente", as trabalhadoras diaristas geralmente têm uma maior carga de trabalho diária que as mensalistas.

O trabalho doméstico requer muito dispêndio de tempo e esforço físico, o que dificulta, se não impossibilita, a realização de outras atividades remuneradas, formalmente registradas ou não, que seriam necessárias para melhores condições de vida, já que o rendimento na ocupação, em média, historicamente tem se mantido abaixo do salário mínimo, para mulheres. Constata-se que $1,1 \%$ das trabalhadoras domésticas realizavam, no primeiro trimestre de 2020, outro trabalho, enquanto 3,05\% das trabalhadoras em geral complementavam, nessa época, seus rendimentos desenvolvendo outra ocupação (PNADC, 2020-1).

Diante desse quadro, o trabalho doméstico em vínculo diário vem se expandindo, tornando-se, na fala das próprias trabalhadoras, uma alternativa às extensas jornadas de trabalho e baixos rendimentos conferidos ao trabalho em vínculo mensal. Marly (39 anos, diarista), que já trabalhou como mensalista residente, mensalista não-residente e hoje é diarista em um domicílio, faxineira em uma clínica e costureira domiciliar, aponta vantagens na articulação dessas três atividades remuneradas a ter que trabalhar como mensalista em uma única residência.

Pra mim tá saindo mais vantajoso porque lá na clínica eles pagam 60 reais mais o almoço e transporte, que vai dá quase oitenta reais cada vez que eu vou. E lá na senhorinha eles dão o almoço, mais setenta reais também, então assim, se eu for olhar pra ponta da caneta dá pra mim tirar por semana 230 reais nos dois serviços. Se eu for trabalhar de doméstica [mensalista] eles vão pagar o salário mínimo e indo todos os dias. Então pra mim compensa mais eu trabalhar esses dois dias da semana e os outros dias em casa [como costureira] do que eu trabalhar fora todos os dias.

Mesmo com as desvantagens que o trabalho em vínculo como diarista oferece, veem como positivas a flexibilidade de horário e de dias trabalhados e a negociação de salários. "A 'opção' por realizar o trabalho de diarista mostrou-se uma forma de "realização" dessas mulheres, uma estratégia de negociação de suas necessidades" (Ribeiro, 2014, p.163).

A articulação trabalho e família exerce papel fundamental nessa estratégia de negociação de suas necessidades, pois é a possibilidade de ter um tempo a mais para a realização do cuidado com família e a casa que pesa na hora de se decidirem sobre trabalhar em vínculo mensal, cumprindo uma jornada pré-estabelecida e amparadas pela legislação, ou abdicar desses direitos e se arriscarem no trabalho informal de vínculo diário, mas com a possibilidade de "fazerem seu próprio tempo".

O tempo para o trabalho doméstico não remunerado parece ser determinante na relação de trabalho doméstico remunerado. Assim também, os usos do tempo dessas trabalhadoras se relacionam ao modo como 
articulam trabalho e família. Para Andrea Delfino, Claudia Herzfeld e Hugo Arrillaga (2015), qualquer análise de usos do tempo deve levar em consideração a estrutura socioeconômica da família, o tipo de família e sua organização, se há membros dependentes no domicílio, entre outras características consideradas chavesexplicativas do modo como as pessoas, sobretudo mulheres, distribuem e fazem uso do tempo.

A composição das famílias em domicílios de trabalhadoras domésticas revela diferenças significativas em relação aos tipos de famílias em domicílios habitados pelas mulheres ocupadas em geral. A Tabela 1 ilustra que a porcentagem de famílias de domésticas compostas por mães e filhos menores que 14 anos é mais de três vezes maior do que em relação a famílias de mulheres ocupadas em geral. A condição de trabalhadora doméstica está associada também a uma porcentagem maior de divórcios, além de que a parcela de mulheres solteiras $(8,12 \%)$ e viúvas $(10,77 \%)$ na ocupação é bem maior do que a que corresponde às mulheres ocupadas em geral (3,42\% e 8,83\%, respectivamente), conforme pode ser visto na Tabela 2 . Essa diferença torna-se ainda mais significativa quando constatamos que a média de idade entre trabalhadoras domésticas em atividade em 2017, 43 anos, é maior que a das mulheres ocupadas em geral, 39 anos. Em Goiânia, conforme já mencionado, a idade média das trabalhadoras domésticas é ainda mais elevada, 49 anos, segundo dados da PNAD Contínua $\left(1^{\circ} \mathrm{tri} / 2020\right)$.

\section{TABELA 1}

Tipo de famílias para todas as unidades domiciliares - Brasil - $2015^{5}$

\begin{tabular}{lll} 
& \multicolumn{2}{r}{$\begin{array}{c}\text { mulheres } \\
\end{array}$} \\
& $\%$ & $\%$ \\
Casal sem filhos & 15,34 & 17,21 \\
Casal com todos os filhos menores de 14 anos & 14,87 & 20,93 \\
Casal com todos os filhos de 14 anos ou mais & 20,38 & 25,27 \\
Casal com filhos menores de 14 anos e de 14 anos ou & & \\
mais & 10,74 & 10,51 \\
Mãe com todos os filhos menores de 14 anos & 6,8 & 2,23 \\
Mãe com todos os filhos de 14 anos ou mais & 16,2 & 10,15 \\
Mãe com filhos menores de 14 anos e de 14 anos ou mais & 4,93 & 1,62 \\
Outros tipos de familia & 10,74 & 12,09 \\
Total & 100 & 100
\end{tabular}

microdados da PNAD - Pessoas e Domicílios, 2015, elaboração própria

TABELA 2

Estado civil de mulheres ocupadas - Brasil - 2015

$\begin{array}{lll} & \% & \% \\ & \text { domésticas } & \text { ocupadas em geral } \\ \text { Casada } & 68,76 & 78,28 \\ \text { Desquitada ou separada judicialmente } & 8,91 & 7,15 \\ \text { Divorciada } & 3,44 & 2,32 \\ \text { Viúva } & 10,77 & 8,83 \\ \text { Solteira } & 8,12 & 3,42 \\ \text { Total } & 100 & 100\end{array}$

microdados da PNAD - Pessoas, elaboração própria

A respeito da idade das trabalhadoras domésticas, estudos anteriores já constataram o progressivo envelhecimento da força de trabalho doméstico e a procura tendencialmente mais baixa pelo trabalho na 
ocupação por pessoas mais jovens (Brites e Picanço, 2013). O levantamento atualizado, mais específico, que realizamos na Figura 2, evidencia a continuidade dessa tendência, no período entre 2012 e 2020-1.

Figura 2

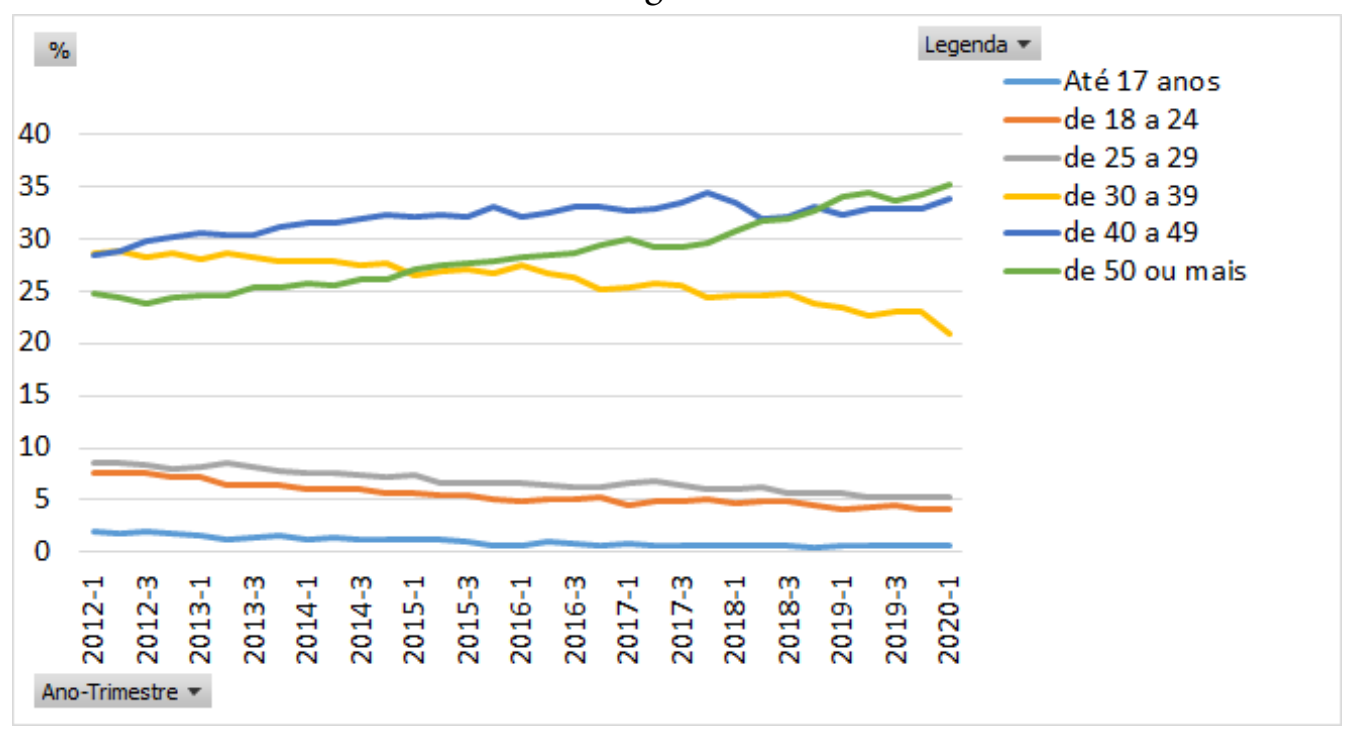

microdados da PNAD Contínua - 2012-1 a 2020-1, elaboração própria

A regulamentação do trabalho doméstico no Brasil teve um avanço significativo com a vigência da Lei Complementar n. 150, a partir de junho de 2015, complementando a Emenda Constitucional n. 72/2013 (PEC das domésticas). Ainda que de forma tardia, já que a ocupação de doméstica constitui uma das mais antigas atividades de trabalho praticadas no Brasil, com raízes na dominação escravista, a regulamentação garante para a trabalhadora doméstica direitos há muito conquistados por outras categorias, como proibição do trabalho de menores de 18 anos, jornada semanal fixa de 44 horas e direito ao Fundo de Garantia por Tempo de Serviço, salário família e seguro desemprego.

Outros países da América Latina, impulsionados pelas recomendações da $100^{a}$ Conferência internacional do trabalho da Organização Internacional do Trabalho em 2011, intitulada "Trabalho decente para trabalhadoras e trabalhadores domésticos", atenderam às reivindicações de movimentos e sindicatos de trabalhadoras que há muitos anos lutavam por direitos básicos já concedidos a outros trabalhadores. $\mathrm{Na}$ Argentina, assim como no Brasil, somente em 2013 as trabalhadoras domésticas tiveram acesso a direitos como jornada de trabalho de 44 horas semanais, com direito a um dia e meio de folga, licença maternidade de três meses, entre outros. A única legislação que amparava essas trabalhadoras argentinas datava de 1956.

No Brasil, a efetivação desses direitos tem enfrentado diversos problemas, como a instabilidade econômica e política que eclodiu no país a partir de 2014. Na época da promulgação da legislação para as trabalhadoras domésticas a conjuntura era de uma progressiva profissionalização na categoria, associada com um decréscimo da taxa de ocupação nessa atividade, diante de um aumento do nível de escolarização e um ciclo ascendente no desenvolvimento econômico do país, acompanhado de medidas de redução da pobreza e proteção de direitos sociais. $\mathrm{Na}$ atual conjuntura, entretanto, tais expectativas são frustradas com o declínio econômico e políticas de retirada de direitos.

Elaboramos um levantamento longitudinal que nos permite acompanhar algumas variáveis importantes nos estudos sobre o trabalho doméstico e alguns resultados estão reproduzidos na Tabela 3. Os valores de rendimento foram deflacionados pelo Índice de Preços ao Consumidor de março de 2020 e os resultados são estimativas para a população, levando em conta os pesos das amostragens complexas realizadas para a PNAD (2003 a 2011) e para a PNAD contínua a partir de 2012. A variável "Trabalho em mais de um domicílio" constitui uma proxy para a forma de contratação como diarista, já que se pode inferir que mensalistas e 
domésticas que residem no mesmo domicílio que o/a empregador/a dificilmente têm condições de trabalhar em outros domicílios. A variável que remete a raça/cor foi construída agregando os valores de pretas e pardas da classificação empregada pelo IBGE na categoria de negras.

O número de trabalhadoras em serviços domésticos permaneceu relativamente estável no período de 2003 a 2019, podendo-se inferir uma leve retração, diante do crescimento da população ocupada no período. O pequeno decréscimo de 4,3\% registrado entre 2011 e 2012 pode ser creditado à maior precisão na captação de trabalhadores no setor, com o deslocamento da designação da categoria de classificação ocupacional "trabalhadores de serviços domésticos em geral" do grupo de serviços pessoais para o grupo de ocupações elementares.

O levantamento durante o período 2012-2019 não reflete algumas especulações que se tornaram populares nos meios de comunicação durante a época que envolveu desde a proposta da PEC até sua consolidação na Lei Complementar de 2015, prevendo desemprego e diminuição de vínculos com carteira assinada. Em relação ao número de vínculos, evidencia-se um decréscimo de $9 \%$ de 2012 a 2019. No entanto, é equivocado considerar que esse decréscimo tenha sido uma consequência direta da crise que viria a se instalar, pois as mulheres ocupadas em geral podem ter se deslocado a outros setores mais qualificados, já que houve um crescimento considerável no nível de escolaridade de mulheres ocupadas de 2012 a 2019, maior do que o correspondente no caso de homens. No caso de mulheres trabalhadoras domésticas o crescimento ainda foi mais expressivo, como se pode verificar na faixa do ensino médio completo, que passou de $16 \%$ em 2012 para 24,9\% em 2017, com base na análise dos microdados da PNADC. No entanto, de acordo com a PNADC de janeiro a março de 2020, 65,75\% das trabalhadoras domésticas têm escolaridade até o ensino fundamental completo e o setor ainda constitui uma oportunidade de trabalho remunerado viável para mulheres pobres, negras e que contam com baixa escolaridade. Em suma, o crescimento no nível de qualificação explica, pelo menos em parte, o deslocamento para outros setores e corrobora o que se tem verificado no interstício da série completa a respeito da remuneração.

No que se refere aos rendimentos, houve um crescimento absoluto e relativo, principalmente no período entre 2003 e 2011. O poder de compra do rendimento de trabalho médio no setor praticamente dobrou de 2003 a 2019. No entanto, até agora o valor médio nunca chegou nem ao valor de um salário mínimo, que, em 2019 foi de 998 reais. Como o salário mínimo teve uma valorização considerável no período, absoluta e relativamente, torna-se difícil creditar esse crescimento preponderantemente às medidas de regulamentação ou a inflexões nas políticas públicas nesse sentido. A informalidade tem diminuído, mas a passo lento e, com a crise e a reforma trabalhista, a partir de 2016 os vínculos com carteira assinada diminuíram, caindo de 32,39\% para 26,97\% em 2019, conforme a tabela 3.

Os dados referentes à Goiânia, no primeiro trimestre de 2020, indicam resultados melhores no que tange à formalização e ao rendimento médio das trabalhadoras quando comparados ao cenário nacional, 34\% têm carteira assinada e o rendimento médio mensal é 1174 reais, um pouco acima do salário mínimo então vigente no país. Acompanhando a tendência de aumento no número de diaristas, aqui consideradas aquelas que trabalham em mais de um domicílio, a capital apresentou um acréscimo de 36,9\%. Apenas 2,9\% tinham mais de um trabalho na semana de referência, ou seja, o trabalho doméstico é a única ocupação da grande maioria das trabalhadoras domésticas em Goiânia

Os resultados de dois outros indicadores parecem sinalizar transformações mais substantivas, em relação a formas de contratação e ao perfil das trabalhadoras domésticas. A primeira mudança está na proporção decrescente de domésticas que residem nos domicílios do/a empregador/a. Conforme visto, esse tipo de vínculo era inicialmente procurado por mulheres mais jovens, mas recentemente não se distingue, no aspecto da faixa etária, de outras formas de contratação, como mensalistas que residem em outro domicílio ou diaristas. Outra transformação é a crescente contratação de diaristas, indicada pelo aumento de domésticas que declaram trabalhar em mais de um domicílio. Há um desnível em 2011-2012, mas que parece decorrer de diferenças técnicas relacionadas à variável "ocupação", gerando melhor identificação das trabalhadoras 
domésticas. O gap não enfraquece a tendência de crescimento de trabalho doméstico em mais de um domicílio. Trabalhar com serviços domésticos em domicílios diferentes não seria possível em contratos como mensalista. Como a maioria nesse tipo de vínculo não tem registro em carteira e a trabalhadora se vê diante da necessidade de se deslocar a vários pontos de trabalho, essa transformação certamente implica maior precarização no trabalho nesse setor de atividades que se caracteriza pela informalidade e ambiguidade entre relações pessoais e laborais.

O terceiro resultado é a preponderância crescente da condição de raça/cor negra na composição da força de trabalho doméstico. Em todos os intervalos da série a taxa de ocupação de mulheres negras como trabalhadoras domésticas é maior que a proporção de mulheres negras na população mulheres ocupada no Brasil. Como dado atual, no período entre janeiro e março de 2020 a taxa de mulheres negras no mercado de trabalho brasileiro era de $51,9 \%$, valor $27 \%$ menor do que a taxa de ocupação de negras como domésticas na mesma época $(65,83 \%)$ (PNADC, 2020-1).

Tabela 3

\begin{tabular}{lllll} 
Ano Ocupadas Rendimento Carteira & Residentes & \multicolumn{2}{l}{ Trabalho em mais de } \\
& assinada $(\%)$ & $(\%)$ & Negras \\
20035.132.505520,71 & 26,21 & 5,14 & 21,37 & 58,16 \\
$20045.451 .986568,78$ & 25,09 & 5,07 & 22,62 & 57,18 \\
$20055.543 .026636,68$ & 25,65 & 4,92 & 23,83 & 60,28 \\
$20065.625 .475712,14$ & 26,75 & 4,64 & 26,22 & 59,85 \\
$20075.567 .990773,41$ & 26,74 & 4,29 & 27,38 & 61,34 \\
$20085.375 .350855,55$ & 26,57 & 3,29 & 29.33 & 61,76 \\
$20095.558 .853962,76$ & 26,89 & 2,85 & 32,61 & 62,29 \\
$20115.137 .397782,68$ & 29,1 & 2,75 & 34,14 & 61,85 \\
$20124.921 .579823,63$ & 31,16 & 2,17 & 27,27 & 64,20 \\
$20134.717 .895862,09$ & 30,50 & 1,70 & 28,70 & 64,79 \\
$20144.710 .348905,26$ & 30,98 & 1,84 & 29,11 & 65,31 \\
$20154.703 .659921,13$ & 31,30 & 1,44 & 30,50 & 65,19 \\
$20164.586 .378903,9$ & 32,39 & 1,51 & 31,85 & 65,44 \\
$20174.378 .775915,16$ & 29,48 & 1,05 & 33,67 & 66,06 \\
$20184.497 .226902,68$ & 27,84 & 1,04 & 35,80 & 66,43 \\
$20194.463 .586902,9$ & 26,97 & 0,95 & 36,13 & 66,97
\end{tabular}

IBGE, microdados-PNAD e PNADC, construção própria

\section{Arranjos e Desarranjos familiares EM torno do trabalho Doméstico REMUNERADO}

No surgimento e desenvolvimento do movimento feminista a problemática do trabalho doméstico (remunerado e não remunerado) ocupou (e ainda ocupa) um lugar de incmodo. Se antes o problema consistia no confinamento das mulheres à esfera doméstica, com a maior absorção da força de trabalho feminina no mercado de trabalho, o dilema passou a girar em torno da equação casa/família e trabalho, e suas implicações; preocupações acompanhadas pelo campo de estudos sobre trabalho e gênero (Fraga, 2016; Boris, 2014; Bilac, 2014; Hirata \& Kergoat, 2007). Isso se deve ao fato de que a maior participação da mulher no mercado de trabalho não foi acompanhada por uma maior participação masculina na esfera doméstica. Portanto, conciliar trabalho e família é tarefa quase que exclusivamente feminina (Urrutia; Faúndez \& Contreras, 2017). Desse modo, segundo Hirata e Kergoat (2007) há uma reconfiguração da divisão sexual do trabalho sem alteração nas bases sobre as quais as relações de gênero são construídas e sustentadas.

Estudos voltados à análise da articulação entre trabalho produtivo e reprodutivo evidenciam a apropriação do tempo das mulheres, com a perda do tempo livre necessário aos cuidados pessoais, descanso e lazer, além da redução do tempo para dedicar-se a outras atividades de desenvolvimento pessoal e coletivo (Carrasco, 
2003; Dedecca, 2004; Rizavi \& Sofer, 2008; Ávila, 2009). Neste ponto é relevante trazer a observação de Elizabeth Souza-Lobo (2011), em estudo sobre as operárias dos anos 1970 e 1980, sobre a dificuldade de mulheres participarem de atividades regulares nos sindicatos, uma vez que, fora do período do trabalho, seu tempo era dedicado à casa e família. A discussão pode ser ampliada para outras atividades de participação coletiva. Por outro lado, para que seja possível equacionar trabalho remunerado e cuidados com a casa e a família, são mobilizadas mulheres em condições de desigualdade para realização do trabalho doméstico de forma remunerada. Estas, por sua vez, em geral recorrem a outras estratégias e improvisam arranjos que lhes possibilitam trabalhar de forma remunerada e atender à responsabilidade com o cuidado da casa e da família.

Em sua maioria, as domésticas são as principais responsáveis pelo trabalho doméstico em seus lares (Santos, 2010; Ávila 2009; Brites \& Picanço, 2013). Exercem, portanto, o trabalho doméstico remunerado e não remunerado. Para o exercício da ocupação as domésticas que têm filhos mobilizam e se apoiam em suas redes familiares, mas também na chamada família extensa, composta por parentes e vizinhas/os. O cuidado e a educação das crianças, filhas das trabalhadoras domésticas transcendem, portanto, o núcleo familiar (Brites \& Picanço, 2013).

No caso aqui analisado, a condição de migrantes internas de todas as domésticas entrevistadas traz especificidades tanto no que tange à composição e organização familiar como aos arranjos domésticos construídos. Por outro lado, a condição de moradora na casa dos/as patróes/as, de sete das entrevistadas, incide de forma significativa nos arranjos domiciliares nas famílias das trabalhadoras domésticas residentes. A mudança de cidade e muitas vezes de estado altera a dinâmica e organização da família que ficou em suas cidades de origem; ademais, morar no local de trabalho traz limites à utilização do tempo e espaço da trabalhadora doméstica.

De modo geral, observou-se que há dois grupos distintos de formação familiar. No primeiro grupo estão aquelas provenientes de famílias monoparentais, nos casos analisados formada pela mãe e seus/as filhos/as. O segundo grupo é de famílias nucleares, compostas por pai, mãe e filhos. No grupo familiar monoparental se encontram as domésticas que já tinham filhos quando migraram de suas cidades de origem. Nesse grupo predominam as trabalhadoras que ajudam ou são as responsáveis financeiramente pela família. Há também algumas características similares aos dois grupos: são famílias numerosas, com mais de dois filhos; há outros membros familiares exercendo o trabalho doméstico remunerado, são famílias advindas das zonas rurais das cidades do interior do estado de Goiás e de outros estados do país, sobretudo da região Nordeste.

Os pais dessas trabalhadoras domésticas, em sua maioria, exercem trabalhos rurais. As mães estão, majoritariamente, no serviço doméstico, o que indica constituir um ciclo passado de mãe para filha. É sugerida uma complementaridade de papéis e atividades exercidos pelos pais. Assim, a inserção no trabalho doméstico remunerado pelas mulheres do núcleo familiar é vista como uma necessidade para complementação da renda. Outras atividades remuneradas, realizados em suas próprias residências, são também assumidas pelas mulheres para contribuição no orçamento familiar. Essas atividades realizadas por mulheres e crianças para aumento da renda familiar não são compreendidas como trabalho, conforme pode ser observado na fala de Fernanda, 29 anos, mensalista residente: "Eu trabalhava em casa quando criança e acho que era uma forma... a gente ganhava dinheiro, mas não era um trabalho. Ajudava minha mãe a destalar pimenta, debulhar alho desde pequena, essas coisas".

Observou-se, desse modo, no que concerne à contribuição no orçamento doméstico, que há uma variedade de arranjos, com mãe, pai e filhos/as agindo; porém, quanto às tarefas domésticas as responsabilidades recaem somente sobre as mulheres. Assim, além de realizarem o trabalho doméstico de forma remunerada, mães e filhas o realizam também em casa.

Nos casos de separação ou perda de algum ente do núcleo familiar, o trabalho doméstico remunerado é concebido como principal meio de resolução dos problemas econômicos provenientes dos desarranjos familiares. Nesses casos, as trabalhadoras recorrem muitas vezes à ajuda de outros familiares. 
Minha mãe sempre morou na roça e trabalhava só lá cuidando dos filhos, porque meu pai mexia com peão na roça e tinha que fazer comida e nós levava a comida naquelas bacias para os peões. A gente fez muito isso porque meu pai cuidava de fazenda assim pros outros. Minha mãe sempre trabalhou assim. Quando meu pai morreu, ela tinha aposentadoria de viúva que é pouco para criar seis filhos e a ajuda maior foi da minha avó, mãe do meu vô. A gente morou com eles até quando eu casei. Nessa época eu e ela fomos trabalhar em casa de família (Beatriz, 54 anos, diarista).

Brites e Picanço (2013) salientam que a redução da condição de filhas entre trabalhadoras domésticas, bem como o aumento de cônjuges e chefes do domicílio, é sinal de que são mulheres com suas próprias famílias constituídas que estão no trabalho doméstico remunerado, aumentando consequentemente o percentual de trabalhadoras com filhos. Esses dados alertam para a necessidade de promoção de políticas públicas que atendam essas mães trabalhadoras domésticas. No entanto, como bem demonstraram as autoras, as domésticas têm recorrido a outras vias, ancoradas principalmente na rede familiar e de vizinhança.

Em etnografia sobre uma comunidade pobre na cidade de São Paulo, no Brasil, Nadya Guimarães e Priscila Vieira (2020) discutem como o cuidado perpassa o cotidiano e a trajetória de mulheres, formando o que denominaram "circuito de cuidados" constituído pelo cuidado profissional, o cuidado como obrigação e o cuidado entendido como ajuda. Segundo as autoras, no cuidado como ajuda as atividades desempenhadas não são entendidas como trabalho e nem como obrigação, "sustentam-se em (e se reproduzem a partir de) relações sociais assentadas na reciprocidade grupal e ou comunitária” (p.10).

Estudos confirmam que, no Brasil, as políticas públicas voltadas à redistribuição ou socialização dos custos de cuidados familiares são insuficientes (Sorj, Fontes \& Machado, 2007; Guedes, 2016). Ademais, "o baixo nível de abrangência das políticas existentes confirma que a gestão das demandas conflitivas entre família e trabalho permanecem em grande medida um assunto privado" (Sorj, Fontes \& Machado, 2007, p. 575).

A construção de políticas que desonerem as mulheres do trabalho reprodutivo esbarra nas representações construídas socialmente com base em um ideário patriarcal de que a principal instituição de cuidado deve ser a família, representada na figura da mãe (Guedes, 2016). Isso, na prática, leva a uma enorme concentração de trabalho doméstico e de cuidados à mulher, esteja ela exercendo trabalho remunerado ou não. Por outro lado, o custo dessa equação "prejudica a quantidade e qualidade da inserção feminina, sobretudo das mães, no mercado de trabalho" (Sorj, Fontes \& Machado, 2007, p.574).

As diversas modalidades do trabalho doméstico remunerado se acomodam em diferentes momentos da vida das trabalhadoras domésticas entrevistadas, principalmente com base na organização familiar. Apenas quatro trabalhadoras domésticas entrevistadas estão na condição de filhas. Outras nove constituíram suas próprias famílias, sendo que sete delas têm filhos, são três casadas, três solteiras e uma divorciada. A necessidade de articular trabalho e família as fazem optar pelo exercício do trabalho doméstico em vínculo diário depois que casam e têm filhos. Entre as sete entrevistadas que residem com os patrões, apenas uma é casada e se encontra cumprindo aviso para deixar o emprego. Destas, duas têm filhos.

A iniciação precoce no trabalho doméstico constitui característica comum a muitas trabalhadoras domésticas (Santana, 2003; Valeriano, 2017). Ao levarem as filhas para o trabalho, as mães, trabalhadoras domésticas, as inserem na ocupação, primeiramente como uma forma de ajuda, realizando pequenas tarefas; com o passar dos anos, algumas delas assumem o trabalho nessas mesmas casas que frequentavam quando crianças, substituindo as mães. A inserção na ocupação se dá, desse modo, como parte de arranjos domésticos construídos pela família, uma estratégia para driblar a deficiência estatal em promover políticas públicas que atendam as mães trabalhadoras, e se sustenta em normas de gênero que atribui às mulheres o trabalho reprodutivo.

A análise das entrevistas que compõem este trabalho evidenciou a formação de outros arranjos domésticos envolvendo o cuidado com os filhos. A construção desses arranjos atende momentos específicos na trajetória das trabalhadoras. No caso das trabalhadoras que tinham filhos quando migraram de suas cidades do interior 
para a realização do trabalho doméstico na cidade de Goiânia, os filhos foram deixados com as avós em suas cidades de origem.

Lisboa (2007) aponta que a migração interna (do campo para a cidade, de uma cidade para outra, no mesmo país) de mulheres para realização do trabalho doméstico, assim como a externa (de um país para o outro), provoca um movimento similar ao que Hochschild (2004) designou como "cadeia global de assistência". Para a autora, a migração de mulheres para o serviço doméstico e o de cuidados estabelece uma cadeia de cuidados de uma ponta a outra, entre raça, classe e nações. No caso das domésticas vinculadas a este trabalho a cadeia de cuidados sustenta-se em dois conjuntos de cuidadoras: a babá (mulher jovem, negra, migrante interna, com pouca escolaridade) que cuida dos filhos da patroa (mulher jovem ou adulta, branca, com alto nível de escolaridade e renda), e a mãe da babá (mulher mais velha, com pouca ou nenhuma escolaridade, trabalhadora rural, negra) que cuida dos netos para que a filha possa trabalhar.

Observou-se também arranjos, ainda minoritários, onde a trabalhadora doméstica, divorciada ou solteira, compartilha o cuidado dos filhos com o pai da criança. Nesses casos, foram expressos sentimentos de estarem negligenciando uma responsabilidade que lhes são conferidas, mas diante das dificuldades encontradas em residirem em uma grande cidade e trabalharem como domésticas, não encontraram outra solução. Marly (39 anos, diarista), que inicialmente morava na residência em que trabalhava, explica que a patroa não deixou que a filha fosse morar com eles; por esse motivo ela ficou com o pai e mesmo após sair da casa dos patrões e residir sozinha, trabalhando como diarista, não encontrou meios de trazê-la:

Ela ficava morando com o pai. Mesmo depois que eu fui morar sozinha eu nem pensei em trazer ela porque trabalhava de dia e praticamente à noite. Chegava em casa só tomava banho, porque no outro dia levantava cedo pra ir trabalhar. Aí a gente pensa assim que se tá com o pai então tá sendo bem cuidada. Porque você ganhar o salário mínimo, pagar aluguel e você pagar uma pessoa pra cuidar do seu filho não tem jeito.

Os arranjos envolvendo a chamada "família extensa" onde a trabalhadora recorre a rede de amigos e vizinhança para provimento do cuidado com os filhos, de forma remunerada ou não, também foram observados. Diferentemente dos outros casos, o arranjo é construído na cidade em que residem, assim, ao final do dia as trabalhadoras domésticas reencontram seus filhos. Esse tipo de disposição se modifica após os filhos alcançarem uma determinada idade onde possam permanecer sozinhos em casa ou se responsabilizarem pelos cuidados com os irmãos mais novos e com os afazeres domésticos, sobretudo quando se trata de mulheres. ${ }^{7}$

O último tipo de arranjo observado constitui um caso atípico envolvendo a família da trabalhadora doméstica e a família contratante. Este é o caso de Lia (62 anos, diarista) que residiu com os patróes por mais de 28 anos e formou sua família junto à família contratante. A sua gravidez não foi, nesse caso, motivo para o abandono da ocupação ou da condição de moradora na casa dos patróes, como ocorreu em diversos casos contemplados na literatura (Valeriano, 2017; Santana, 2003; Borgeaud-Garciandía, 2017). A família contratante acolheu o filho da empregada dando-lhe a liberdade que a mãe não possuía.

Os contornos desse arranjo evidenciam ainda outro fato curioso:

Depois de velha passei no concurso do Estado em 1993. Eu morava no meu serviço, eu trabalhava de doméstica e trabalhava no colégio. Ela [a patroa] aposentou e ela olhava o meu filho porque eu trabalhava a noite na escola, ela chegava seis horas e eu saía seis horas e ela tomava conta. Ela que cuidava dele, isso até ele dar conta de se virar sozinho (Lia, 62 anos, diarista/cuidadora).

Esse tipo específico de arranjo familiar provocou conflitos entre os valores adquiridos pela trabalhadora doméstica e aqueles defendidos pela família contratante, disputando a educação da criança. A convivência fez com que a criança considerasse também, como pais, os patrões da mãe; e, somente depois de o filho tornarse adulto, mãe e filho foram morar sós.

Apesar da proximidade e afeto partilhados na relação, nos mais de 28 anos em que trabalhou e residiu com essa família, Lia sempre recebeu salários muito baixos. Apenas depois de 18 anos de trabalho para a mesma família é que teve a sua carteira de trabalho assinada. Quando ela saiu do emprego não recebeu nenhum de 
seus direitos. Em relação à jornada de trabalho, Lia pontua: "era de domingo a domingo. Eu só ia visitar meus pais de seis em seis meses que era quando ela [a patroa] viajava com os meninos” (Lia, 62 anos).

Esse caso é emblemático para ilustrar a relação ambígua de afeto e desigualdade no trabalho doméstico remunerado, fenômeno que recentemente tem ganhado espaço nas análises sobre o tema do trabalho doméstico no Brasil (Brites, 2007; Monticelli, 2013) e em outros países da América Latina (Canevaro, 2009; Gutiérrez-Rodríguez, 2014; Gorbán \& Tizziani, 2019). Em análise sobre o contexto argentino de trabalho doméstico remunerado, Gorbán \& Tizziani (2019) propóem o conceito de "repertórios de demarcação" para explicar a separação espacial e do que chamou de "mundo dos sentidos" de domésticas e empregadoras. Para as autoras, essas separações, camufladas em relações afetivas, constituem-se em importantes ferramentas de construção e sustentação das hierarquias e desigualdades no trabalho doméstico. Desse modo, oculta-se a relação de trabalho por meio da afetividade, dificultando o acesso aos direitos, que para as trabalhadoras domésticas argentinas, assim como para as brasileiras, foram tardiamente reconhecidos.

De modo geral pode-se dizer que os arranjos de conciliação construídos em famílias e domicílios das domésticas vinculadas reproduzem, em parte, as relações de subordinação que deram origem à própria migração de trabalhadoras do interior para as capitais. Por outro lado, arranjos familiares específicos na casa dos/as patrões/as evidenciam a ambiguidade da identidade ocupacional da trabalhadora doméstica.

\section{Considerações Finais}

O artigo buscou analisar a relação trabalho e família vivenciada por mulheres em serviços domésticos no Brasil. A ênfase incide sobre arranjos domésticos no domicílio de origem das trabalhadoras domésticas e para isso recorreu-se a dados quantitativos e qualitativos, referentes ao cenário nacional e à cidade de Goiânia em particular, que nos permitiu atentar para os aspectos objetivos e subjetivos da relação trabalho e família. A abordagem mostrou-se relevante para a análise do problema, pois permitiu situá-lo numa arena em que os aspectos macro e micro da ocupação se relacionam. Se por um lado a economia e as mudanças nas legislações trabalhistas trouxeram novas dinâmicas à ocupação, por outro, os arranjos domésticos e as configurações familiares das trabalhadoras se mostraram elementos importantes para compreendermos alguns processos precarizantes que subsistem em diferentes cenários em que prevalece o trabalho doméstico.

Constata-se, na esteira de Brites (2013) e Colen (1995), que o trabalho doméstico e suas diversas atividades têm sido distribuídos de acordo com hierarquias de classe, gênero, raça e origem geográfica. A precariedade no trabalho doméstico remunerado expressa sobretudo nos altos índices de informalidade e nos baixos rendimentos auferidos é evidente, tanto na análise do cenário nacional como no caso de Goiânia. Sete anos após a conquista de novos direitos pela categoria no Brasil, os indicadores observados não são muito promissores.

As diferentes modalidades de trabalho doméstico acomodam-se às trabalhadoras em momentos distintos de suas vidas, de modo que arranjos familiares e trabalho doméstico incidem direta e indiretamente sobre um e outro. Nesse movimento de construção de arranjos para liberar a mulher para o exercício do trabalho doméstico e de acomodação em uma modalidade de trabalho doméstico remunerado para conciliação com a família, o Estado, enquanto provedor de condições básicas para uma vida humana digna, não cumpre o seu papel de forma satisfatória. Embora se possa identificar um avanço na regulação do trabalho doméstico, inclusive em comparação com a legislação em outros países, percebe-se que ainda há uma considerável distância na efetivação dos direitos dessas trabalhadoras, o que se torna ainda mais evidente em tempos de crise e pandemia. Em termos gerais, além de medidas relacionadas à fiscalização e regulação de trabalho, é preciso pensar novas políticas para trabalhadoras e famílias, centradas na socialização e desgenerificação dos custos do cuidado.

A pobreza e os desarranjos familiares parecem se constituir, nos casos observados, uma das molas propulsoras para inserção precoce na ocupação. Ao passo que, se de um lado homens e mulheres que pagam 
pelo serviço doméstico se beneficiam dele para o exercício de suas profissões, as trabalhadoras domésticas inseridas num ciclo de reprodução da própria condição subalterna, transferem em muitos casos a ocupação para as filhas. Concorda-se com Melo (1998) de que há um movimento em torno do trabalho doméstico e de cuidados que possibilita a entrada e permanência das mulheres dos estratos de renda médios e altos no mercado de trabalho, mas não são criados, em contrapartida, serviços coletivos que possibilitem, de forma ampla e satisfatória, a socialização ou a redistribuição dos cuidados.

Os vários arranjos construídos pelas trabalhadoras domésticas para articulação entre trabalho e família evidenciam que, além da permanência da figura feminina como principal agente responsável pelo cuidado com a casa e a família, o compartilhamento dessas responsabilidades também acontece principalmente entre mulheres, sejam elas mães, filhas, avós, amigas, vizinhas, responsabilidades assumidas mediante pagamento ou não. Portanto, não se altera a dinâmica das normas de gênero em torno do provimento do cuidado com a casa e a família. A presença masculina se mantém nesses casos, salvo em raríssimas exceções, fora dos arranjos domésticos construídos. Assim também permanece a figura do Estado.

As diversas condições desfavoráveis a que estão submetidas as trabalhadoras domésticas se entrelaçam formando uma teia de desigualdades, comprometendo-lhes a cidadania. Se, por um lado, a conquista de novos direitos rompe com a invisibilidade das trabalhadoras domésticas promovendo-lhes melhores condições de trabalho, é bastante sombrio o cenário que se constrói a partir da reforma trabalhista e da série de retrocessos nos direitos sociais no Brasil.

\section{REFERÊNCIAS}

Acciari, L., \& Pinto, T. (2020). Praticando a equidade: Estratégias de efetivação de direitos no trabalho doméstico. Estudos Avançados, 34(98), 73-90. https://doi.org/10.1590/s0103-4014.2020.3498.006

Albieri, S. \& Bianchini, Z. (2015). Principais Aspectos de Amostragem das Pesquisas Domiciliares do IBGE - Revisão 2015 / IBGE (pp. 1-54). Rio de Janeiro: IBGE. Recuperado de https://biblioteca.ibge.gov.br/visualizacao/livr os/liv94403.pdf

Ávila, M. (2009). O tempo do trabalho das empregadas domésticas: tensões entre dominação/exploração e resistência. Recife: Editora da Universidade Federal de Pernambuco.

Bento, P. (2016). Mensalistas e diaristas: as implicaçôes pertinentes às relaçôes entre famílias, rendimento e direitos de trabalhadoras domésticas. (Dissertação de mestrado). Sociologia, Universidade de Brasília, Brasília, Brasil. Recuperado de: https://repositorio.unb.br/bitstream/10482/22714/1/2016_PauloDoniseteBento.pdf

Bernardino-Costa, J. (2015). Decolonialidade e interseccionalidade emancipadora: a organização política das trabalhadoras domésticas no Brasil. Sociedade e Estado, 30, 147-163. https://doi.org/10.1590/S0102-6992201 5000100009

Bilac, E. (2014). Trabalho e família: Articulações possíveis. Tempo social, 26(1), 129-145. https://doi.org/10.1590/S 0103-20702014000100010

Borgeaud-Garciandía, N. (2017) Trayectorias de vida y relaciones de dominación. Las trabajadoras migrantes en Buenos Aires. Revista Estudos Feministas, 25(2), 757-776. https://doi.org/10.1590/1806-9584.2017v25n2p7 57

Boris, E. (2014) Produção e reprodução, casa e trabalho. Tempo social, 26(1), 101-121. Recuperado de https://www .scielo.br/pdf/ts/v26n1/08.pdf

Brites, J. \& Picanço, F. (2013). O emprego doméstico em números, tensões e contradições: alguns achados de pesquisas. In 37 aReunião da ANPOCS, Águas de Lindóia.

Brites, J. (2007). Afeto e desigualdade: gênero, geração e classe entre empregadas domésticas e seus empregadores. Cadernos Pagu, 29, 91-109. https://doi.org/10.1590/S0104-83332007000200005

Brites, J. (2013). Trabalho doméstico: questões, leituras e políticas. Cadernos de Pesquisa, 43(149), 422-451. https:// doi.org/10.1590/S0100-15742013000200004 
Bruschini, C. (2006). Trabalho doméstico: inatividade econômica ou trabalho não-remunerado? Revista Brasileira de Estudos Populacionais, 23(2), 331-353. https://doi.org/10.1590/S0102-30982006000200009

Canevaro, S. (2009). Empleadoras del servicio doméstico en la Ciudad de Buenos Aires: intimidad, desigualdad y afecto. Avá, 15(2), 187-207.

Cardoso, A. (2013). Organização e intensificação do tempo de trabalho. Sociedade e Estado, 28(2), 351-374. https:// doi.org/10.1590/S0102-69922013000200009

Carrasco, C. (2003). ¿Conciliación? No, gracias. Hacia una nueva organización social. En Amoroso, M. et al., Malabaristas de la vida. Mujeres, tiempos y trabajos (pp.27-51). Barcelona: Icaria.

Colen, S. (1995). Like a mother to them: stratified reproduction and West Indian childcare workers and employers in New York. In Ginsburg, F. \& Rapp, R. (Org.). Conceiving the new world order: the global politics of reproduction (pp. 78-102). Berkeley: University of California Press.

Dal Rosso, S. (2008). Mais trabalho! A intensificação do labor na sociedade contemporânea. São Paulo: Boitempo.

Dedecca, C. (2004). Tempo, trabalho e gênero. In Bezerra, M. et al. (Org.). Reconfiguração das relações de gênero no trabalho (p. 21-52). São Paulo: CUT Brasil.

Delfino, A.; Herzfeld, C. \& Arrillaga, H. (2015). Trabajo doméstico no remunerado y uso del tiempo en la Provincia de Santa Fe: una caracterización hacia 2013. Revista de Estudios Regionales (11), 35-57.

Fraga, A. (2016). O serviço doméstico sob os holofotes públicos: alterações na articulação entre trabalho produtivo e reprodutivo no Brasil (Estado, mercado e família). (Tese de doutorado). Programa de Pós-Graduação em Sociologia e Antropologia da Universidade Federal do Rio de Janeiro. Rio de Janeiro.

Gorbán, D. \& Tizziani, A. (2014). Inferiorization and deference: The construction of social hierarchies in the context of paid domestic labor. Women's Studies International Forum, 46, 54-62. Recuperado de https://daneshyari.c om/article/preview/375986.pdf

Gorbán, D. \& Tizziani, A. (2019). ¿Cada una en su lugar? Trabajo, género y clase en el servicio doméstico. Buenos Aires: Editorial Biblos.

Graham, S. L. (1992). Proteção e Obediência: criadas e seus patrões no Rio de Janeiro - 1860 - 1910. São Paulo: Cia das Letras.

Guedes, M. (2016). Percepções sobre o papel do Estado, trabalho produtivo e trabalho reprodutivo: uma análise do Rio de Janeiro. Cadernos Pagu, 47, e164720. https://doi.org/10.1590/18094449201600470020

Guimarães, N. \& Vieira, P. (2020). As “ajudas”: o cuidado que não diz seu nome. Estudos Avançados, 34(98), 7-24. h ttp://dx.doi.org/10.1590/s0103-4014.2020.3498.002

Gutiérrez-Rodríguez, E. (2014). Domestic work-affective labor: on feminization and the coloniality of labor. Women's Studies International Forum, 46, 45-53.

Hirata, H. \& Kergoat, D. (2007). Novas configurações da divisão sexual do trabalho. Cadernos de Pesquisa, 37(132), 595-609. Recuperado de https://www.scielo.br/pdf/cp/v37n132/a0537132.pdf.

Hochschild, A. (2004). As cadeias globais de assistência e a mais-valia emocional. In Hutton, W. \& Giddens, A. No limite da racionalidade - convivendo com o capitalismo global (pp. 187-209). Rio de Janeiro: Record.

IBGE (2017). Pesquisa Nacional por Amostra de Domicílios Contínua. Rio de Janeiro: IBGE (Notas técnicas - Versão $1.4)$.

Kergoat, D. (2009). Divisão sexual do trabalho e relações sociais de sexo. In: HIRATA, H. at al. Dicionário crítico do feminismo (pp.67-75). São Paulo: UNESP.

Lisboa, T. (2007). Fluxos migratórios de mulheres para o trabalho reprodutivo: a globalização da assistência. Estudos Feministas, 15(3), 805-821. Recuperado de: https://periodicos.ufsc.br/index.php/ref/article/download/S0104 $-026 \mathrm{X} 2007000300017 / 1620$

Mattoso, K. (1982). Ser escravo no Brasil. São Paulo: Brasiliense.

Melo, H. (1998). De criadas a trabalhadoras. Estudos Feministas, 6(2), pp.323-357. Recuperado de: https://periodic os.ufsc.br/index.php/ref/article/download/12011/11297 
Monticelli, T. (2013). Diaristas, afeto e escolhas: ressignificações no trabalho doméstico remunerado. (Dissertação de mestrado), Sociologia, Universidade Federal do Paraná, Curitiba, Brasil.

ONU Mulheres, OIT e CEPAL. (2020). Trabalhadoras domésticas remuneradas na América Latina e no Caribe frente à crise da COVID-19. BRIEF v 1.1.

Pérez, I., Cutuli, R. \& Garazi, D. (2018). Senderos que se bifurcan. Servicio doméstico y derechos laborales en la Argentina del siglo XX. Mar del Plata: EUDEM.

Ribeiro, C. (2014). Usos de si e (in)formalidade no trabalho da empregada doméstica diarista. (Tese de doutorado), Educação, Universidade Federal de Minas Gerais, Belo Horizonte, Brasil.

Rizavi, S. \& Sofer, C. (2008). Trabalho doméstico e organização do tempo dos casais: uma comparação internacional. In Costa, A. et al. (orgs.). Mercado de trabalho e gênero: comparaçôes internacionais. Rio de Janeiro: Editora FGV.

Santana, M. (2003). As condições e o sentido do trabalho doméstico realizado por adolescentes que residem no local de emprego. (Dissertação de mestrado), Psicologia, Universidade Federal do Rio Grande do Norte, Natal, Brasil. Recuperado de https://repositorio.ufrn.br/jspui/handle/123456789/17505

Santos, N. (2010). Desigualdade e identidade no serviço doméstico: interseç̧ôes entre classe, raça e gênero. (Dissertação de mestrado), Sociologia. Universidade Federal de Goiás, Goiânia, Brasil. Recuperado de http://repositorio.bc .ufg.br/tede/handle/tde/1600

Sorj, B; Fontes, A. \& Machado, D. (2007). Políticas e práticas de conciliação entre família e trabalho no Brasil. Cadernos de Pesquisa, 37(132). https://doi.org/10.1590/S0100-15742007000300004

Souza-Lobo, E. (2011). A classe operária tem dois sexos. Trabalho, Dominação e Resistência. São Paulo: Editora Fundação Perseu Abramo.

Urrutia, V; Faúndez, O. \& Contreras, C. (2017). Negociaciones en familia: género, trabajo y cuidado en Chile. Revista Estudos Feministas, 25(2), 661-668.

Valeriano, M. M. (2017). Elas são quase da familia: trabalho, identidades e trajetórias de trabalhadoras domésticas residentes. (Dissertação de mestrado), Sociologia, Universidade Federal de Goiás, Goiás, Brasil.

Vazquez Lorda, L. \& Pérez, I. (2019). Fe y Trabajo: servicio doméstico, asociaciones católicas y género en los años cincuenta. Descentrada, 3(2), e089. https://doi.org/10.24215/25457284e089

Vieira, N. \& Almeida, T. (2019). O trabalho doméstico e as babás: lutas históricas e ameaças atuais. Sociedade e Cultura, 22(1), 135-156. https://doi.org/10.5216/sec.v22i1.57899

Vinuto, J. (2014). A amostragem em bola de neve na pesquisa qualitativa: um debate em aberto. Temáticas, 22(44), 203-220. https://doi.org/10.20396/temáticas.v22i44.10977

\section{EnTREvistas}

Marly (2016). Entrevista realizada por Marta Maria Valeriano a trabalhadora doméstica diarista Marly, na cidade de Goiânia, Goiás, Brasil, em setembro de 2016.

Beatriz (2016). Entrevista realizada por Marta Maria Valeriano a trabalhadora doméstica diarista Beatriz, na cidade de Goiânia, Goiás, Brasil, em outubro de 2016.

Lia (2016). Entrevista realizada por Marta Maria Valeriano a trabalhadora doméstica diarista Lia, na cidade de Goiânia, Goiás, Brasil, em outubro de 2016

Fernanda (2016). Entrevista realizada por Marta Maria Valeriano a trabalhadora doméstica residente Fernanda, na cidade de Goiânia, Goiás, Brasil, em dezembro de 2016

\section{Notas}

1 A informação tem por base os microdados da Pesquisa Nacional por Amostra de Domicílios Contínua - PNADC referentes ao trimestre jan/mar de 2020. Os levantamentos realizados demandaram consulta a diversas obras de referência sobre a PNAD, na antiga versão anual e na atual contínua (trimestral), dentre as quais destacaram-se o Texto 
para Discussão de Albieri e Bianchinni (2015) e as notas técnicas publicadas pelo IBGE sobre a PNAD Contínua (2019). O aplicativo utilizado para análise estatística foi o Stata.

2 Em decorrência da atribuição das responsabilidades com a casa e a família às mulheres, a relação de trabalho doméstico remunerado se estabelece primordialmente entre patroas e empregadas. É nesse sentido, ainda, que optamos por manter a designação da ocupação no feminino ("trabalhadoras domésticas").

3 Todas as informaçôes sobre rendimentos estão deflacionadas pelo IPCA (índice de preços ao consumidor) de março de 2020, ou seja, expressam o valor de compra estimado nesta data.

4 Como a PNAD anual foi descontinuada em 2016 e a PNAD contínua não inclui dados sobre composição familiar os dados não foram, neste aspecto, atualizados.

5 Não foi possível, até esta data, realizar esse tipo de levantamento com base na PNAD contínua, que ainda não inclui dados sobre tipos de família e estado civil.

6 Em 2010 não ocorreu o levantamento da PNAD, já que foi realizado o Censo Demográfico.

7 Dados divulgados pelo IBGE, referentes à PNAD contínua de 2016, revelam que o trabalho doméstico e de cuidados é responsável pela exclusão de $26,1 \%$ das adolescentes e jovens do sistema escolar. Disponível em: https://agenciadenoticias.ibge.gov.br/agencia-noticias/2012-agencia-de-noticias/noticias/18993-das-jovens-forada-escola-26-alegam-cuidar-da-casa-de-criancas-ou-idosos.html 